\title{
GPPS-BJ-2019-0018
}

\section{EXPERIMENTAL STUDY ON SPATIO-TEMPORAL VARIATION OF DOUBLE-ROW HOLES FILM COOLING EFFECTIVENESS WITH OSCILLATING MAINSTREAM}

\author{
Han Chen, Wenwu Zhou“, Mohamed Qenawy, Yingzheng Liu \\ School of Mechanical Engineering, Shanghai Jiao Tong University \\ 800 Dongchuan Road, 200240 Shanghai, China \\ *zhouww@sjtu.edu.cn
}

\begin{abstract}
The effect of mainstream oscillations on double-row holes film cooling effectiveness was experimentally investigated. During the experiment, carbon dioxide $\left(\mathrm{CO}_{2}\right)$ was used as the coolant and was discharged from $35^{\circ}$ inclined double-row holes with in-line and staggered arrangement. As a baseline study, a single row injection was pre-considered and the double-row film cooling cases with periodic freestream were assessed in detail to explore the frequency effect (i.e. set to $5 \mathrm{~Hz}$ and $25 \mathrm{~Hz}$ with fixed amplitude) on adiabatic effectiveness. The adiabatic effectiveness was measured by fast-response pressuresensitive paint (fast-PSP) and was further analysed in term of the time-averaged $(\bar{\eta})$ and phase-averaged $(\tilde{\eta})$ results. The time-averaged results showed that double-row could restrain the negative effects of mainstream oscillations and enhance the positive effects, compared with the baseline. The phaseaveraged results showed that the double-row could have more stable coolant coverage than single row. Moreover, the staggered arrangement had comprehensive better protection than the in-line at high blowing ratio, but at lower blowing ratio reversed.
\end{abstract}

\section{INTRODUCTION}

As an advanced cooling technology, film cooling is widely used in high temperature key components such as turbines and combustors. The cold air extracted from the compressor is ejected through film cooling holes, then a thin cold film is formed to attach to the surface of extreme high temperature components to isolate the hot gas (Bogard et al, 2006). Undoubtedly, a stable and uniform coolant coverage is critically needed for the sustainable operation of gas turbine. To this day, various studies have been conducted to understand the fundamentals of film cooling, with the steady and uniform mainstream (Han et al, 2012). In fact, the flow over the film-cooled surface is highly unsteady due to the rotor-stator interactions or even behaves like an oscillating flow resulting from combustion instability (Beak et al, 2016). And the unsteady flow often features near-sinusoidal oscillations (Beak et al, 2017). The oscillated flow would make the film cooling process complicated, leading to a highly unsteady coolant coverage over the wall surface. With the unsteady coolant coverage, the vital components may partially or completely exposure to hot gas during film cooling, over a long period, which may lead to engine failure. Thus, it is highly desirable to quantify the effect of mainstream oscillations on adiabatic effectiveness, including both the time-averaged and phase-averaged results.

As to the studies of film cooling under oscillating mainstream, Ligrani (Ligrani et al, 1996) used the hotwire anemometer and flow visualization techniques to study the coolant behaviours and flow structure. Measured results showed two distinct film behaviours, quasi- and non-quasisteady behaviours, which depended on the value of the coolant Strouhal number. Seo (Seo et al, 1998) conducted a similar study and found a decrease of 50\% in effectiveness as the oscillating frequency grew from $2 \mathrm{~Hz}$ to $32 \mathrm{~Hz}$. Recently, using the fast-pressure-sensitive-paint (fast-PSP) technique, Zhou (Zhou et al, 2019) reported the effects of mainstream oscillations on a single round cooling hole. Results indicated that with the oscillation frequency increased from $0 \mathrm{~Hz}$ to 20 $\mathrm{Hz}$, at blowing ratio $M=0.4$ and 0.8 , the ensemble-averaged adiabatic effectiveness would decrease $33 \%$ and $14 \%$ respectively.

The above studies on film cooling under mainstream oscillation are single film cooling hole. In fact, in order to maintain effective film coverage, multiple rows of holes are machined on the blade surface. With steady-state mainstream, film cooling with double row holes is also widely studied. Ligrani (Ligrani et al, 1994) studied the film cooling of double row holes, the results showed that the double row holes had better cooling performance than single 
hole at high blowing ratio. In addition, when the blowing ratio is $0.2 \sim 0.6$, the cooling effectiveness of staggered arrangement holes is higher than counterpart of in-line arrangement. For unsteady mainstream condition, Sohn (Sohn et al, 1997) studied the effect of bulk flow pulsations on double-row cooling holes for blowing ratio 0.5 and 1.0. The results indicated that all the cooling effectiveness were reduced compared to no-pulsation case, especially for staggered arrangement with more than $35 \%$ reduction.

The effect of mainstream oscillation on film cooling effectiveness of double-row holes was studied in this paper. Different from Sohn (Sohn et al, 1997), the amplitude of oscillating mainstream was fix for better understanding the effect of frequency. In fact, the oscillation frequency of high temperature gas from combustion chamber varies from several $\mathrm{Hz}$ to thousands of $\mathrm{Hz}$. However, this paper focused on the low frequency region, and chooses the oscillation frequencies of $5 \mathrm{~Hz}$ and $25 \mathrm{~Hz}$ (Beak et al, 2016). In the experiment, carbon dioxide $\left(\mathrm{CO}_{2}\right)$ was used as cooling gas, and the blowing ratio $M=0.4$ and 0.8 were taken, which passed through double-row cooling holes with an inclined angle of $35^{\circ}$ and then covered on the experimental plate. In addition, film cooling effectiveness was obtained by fast-PSP technology which could illustrate the measurement of whole region.

\section{EXPERIMETAL APPARATUS AND TECHNIQUES}

\section{Wind tunnel and test model}

The experimental studies were conducted in a lowspeed, open-circuit, suction wind tunnel located at the Department of Mechanical Engineering of Shanghai Jiao Tong University. The wind tunnel, shown in Figure 1, has an optically transparent test section with a cross section of 150 $\mathrm{mm} \times 100 \mathrm{~mm}$, and a plenum to supply the film cooling jets. With honeycombs and screen installed at the inlet and the exit of the nozzle contraction respectively, the tunnel can supply a uniform low-turbulence oncoming flow into the test section. The turbulence intensity of the mainstream was $3 \%$ measured by hotwire anemometer (Dantec, 55P11). A $5 \mathrm{~cm}$ wide 30 grit sandpaper was pasted at the end of nozzle contraction to trip the oncoming flow to ensure a fully developed turbulent boundary layer over the test section. With a steady mainstream $\bar{U}_{\infty}=8 \mathrm{~m} / \mathrm{s}$, the boundary layer profile was measured upstream of the cooling holes (without coolant flow), and was determined to resemble a fully developed turbulent boundary layer with thickness $\delta \approx 1.9 D$ and momentum thickness $\delta^{* *} \approx 0.2 D$.

The coolant supply plenum is a chamber with $0.08 \mathrm{~m} \times$ $0.11 \mathrm{~m} \times 0.16 \mathrm{~m}$ inside dimensions. It is connected to a high-pressure tank by a manifold. The high-pressure tank has 99.99\% purity $\mathrm{CO}_{2}$ gas as the coolant source. During the experiment, the coolant jet flow $\left(\mathrm{CO}_{2}\right.$ gas), with a density ratio $\left(\mathrm{DR}=\rho_{c} / \rho_{\infty}\right)$ of 1.53 , passed through a pipeline and a constant temperature water bath to reach an equivalent temperature with the mainstream and a control valves before entering the plenum chamber. With the buffer inside the plenum, the velocity of coolant was slow enough, so the blowing ratio $\left(M=\rho_{c} \bar{U}_{c} / \rho_{\infty} \bar{U}_{\infty}\right)$ could be controlled by the volume flowmeter (Omega, FMA-1610A) which uncertainty level less than $1 \%$.

In present study, double-row holes test models included in-line and staggered arrangement, shown in Figure 2. The diameter $(D)$ of these round cooling holes is $5 \mathrm{~mm}$ and the first upstream row is located at $81 D$ downstream from the inlet of the test section. The span-wise pitch $(p)$ between adjacent holes is $4 D$, and the spacing $(s)$ between two rows is $3 \mathrm{D}$. Origin of streamwise coordinate $(x)$ is located at the centre of the second-row holes. The grey block depicted in Figure 2 (a), is the region which indicated the contour of the experimental result, and the area which is enclosed by the dashed line $(-4 D \leqslant z \leqslant 4 D)$ would be used to demonstrate the laterally averaged results. All the test models are made of a hard-plastic material and manufactured by a rapid prototyping 3D-printer which build the models layer-by-layer with a resolution of about 50 microns. Figure 2 (b) shows the top and cross view of the test section.

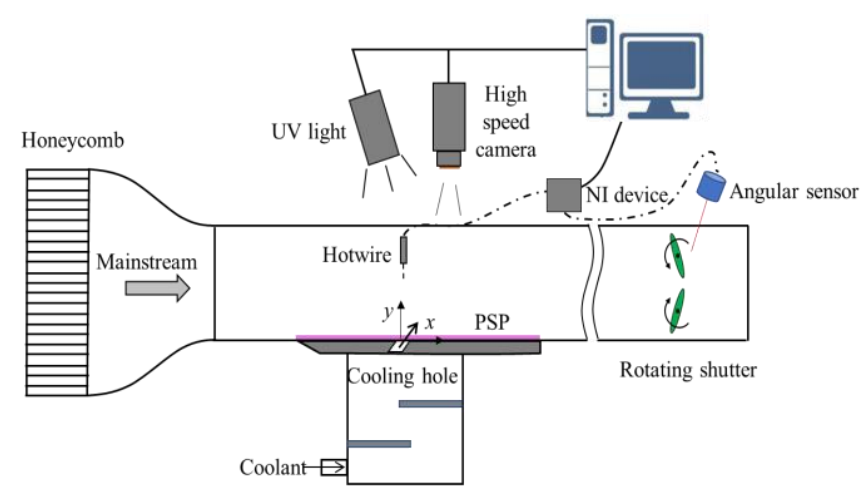

Figure 1 Schematic of experimental apparatus

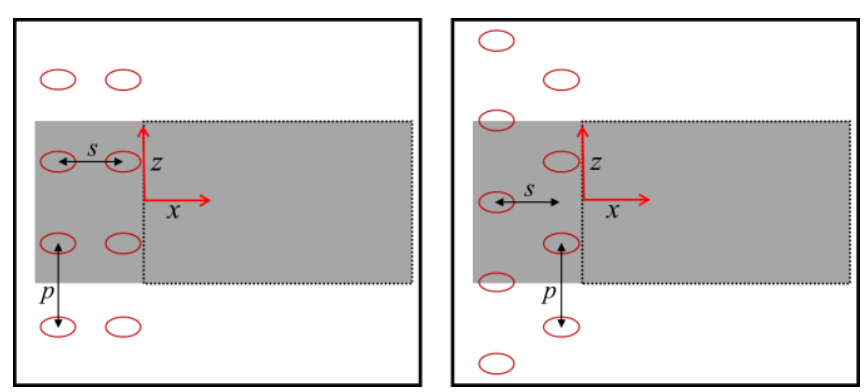

(a) Film cooling hole arrangements and region of interest
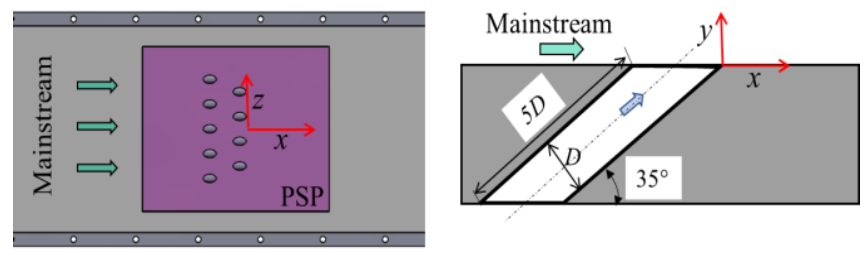

(b) Test section top and cross view

Figure 2 Film cooling test models 


\section{PSP technique and experimental set up}

In present study, a fast-PSP (PtTFPP as a luminophore) with a dynamic frequency response up to $6 \mathrm{kHz}$ measured by shock tube was applied on the test surface to quantify the adiabatic effectiveness, which was a method initially developed by Scroggin et al (Scroggin, et al, 1999). and developed by Gregory et al (Gregory, et al, 2008). It is a mass transfer technique, and has been widely utilized as a reliable method to measure film cooling effectiveness over a flat plate.

PSP is a photoluminescent material, it consists of luminescent molecules being held together by a gaspermeable polymeric binder. When excited by certain UV light (385 $\mathrm{nm}$ in present study), it will emit light with a longer wavelength, and the intensity of the released light is proportional to surrounding partial pressure of oxygen via a process called oxygen quenching (Bell, et al, 2001). The relationship between the emitted light and the partial pressure of oxygen can be described by the Stern-Volmer equation (Liu, et al, 2005):

$$
\frac{I_{r}-I_{b}}{I-I_{b}}=A(T)+B(T) \frac{p_{\mathrm{O}_{2}}}{p_{\mathrm{O}_{2}, r}} .
$$

Where $I_{r}$ and $p_{\mathrm{O}_{2}, r}$ are the emission intensity and the partial oxygen pressure respectively, with the UV light on. $I_{b}$ is the background light intensity, with UV light off. Due to the emission light wavelength is longer than the UV source, we can segregate the source light intensity and the background noise by adding filter on the camera lens. The temperature-related coefficients A and B are obtained from the calibration curve which is shown in Figure 3.

Adiabatic film cooling effectiveness is typically defined as a nondimensional temperature

$$
\eta=\frac{T_{\infty}-T_{a w}}{T_{\infty}-T_{C}} .
$$

where $T_{\infty}$ is the mainstream flow temperature, $T_{a w}$ is the adiabatic wall temperature, and $T_{c}$ is the coolant temperature at the hole exit. The value of $\eta$ is 1 represents a perfect coolant coverage on the surface, whereas that $\eta$ is 0 denotes no coolant coverage. Based on mass transfer analogy, the adiabatic effectiveness Eq. (2) can be further expressed as Eq. (3) (Charbonnier et al, 2009), where the $M W$ is the coolant to mainstream molecular weight ratio (i.e. 1.53 for $\mathrm{CO}_{2}$ gas).

$$
\begin{gathered}
\eta=\frac{T_{\infty}-T_{a w}}{T_{\infty}-T_{C}}=\frac{\left(C_{O_{2}}\right)_{\text {main }}-\left(C_{O_{2}}\right)_{\text {mix }}}{\left(C_{O_{2}}\right)_{\text {main }}-\left(C_{O_{2}}\right)_{\text {coolant }}}=1- \\
\frac{1}{\left[\left(\left(p_{O_{2}}\right)_{\text {air }} /\left(p_{O_{2}}\right)_{\text {mix }}\right)_{\text {wall }}-1\right] M W+1} .
\end{gathered}
$$

To calculate the adiabatic effectiveness, the specific approaches are divided to four steps. As the Figure 1 shows, Step 1, with the wind tunnel running and $\mathrm{CO}_{2}$ as coolant injection, turn on the UV light, the light intensity $I_{\text {mix }}$ which reflects the $\left(p_{\mathrm{O}_{2}}\right)_{\text {mix }}$ in Eq. (3) can be recorded by the high-speed camera (PCO HS4). Step 2, with the wind tunnel on and air as coolant injection, turn on the UV, record the intensity $I_{\text {air }}$ which represents the $\left(p_{\mathrm{O}_{2}}\right)_{\text {air }}$. Step 3, with the wind tunnel off and no coolant injection, turn on the
$\mathrm{UV}$, record the reference intensity $I_{r}$. Step 4, with the wind tunnel off and no coolant injection, turn off the UV, record the background intensity $I_{b}$. Finally, we can get $\left(p_{\mathrm{O}_{2}}\right)_{\text {air }} /$ $\left(p_{\mathrm{O}_{2}}\right)_{\text {mix }}$ which can be further determined the adiabatic effectiveness, according to the calibration curve.

All the PSP experiments were conducted under isothermal condition (i.e. the temperature between mainstream and coolant is quite similar, controlled by the water bath), thus we can easily eliminate the heat conduction related errors which is the main challenge associated with the temperature-based measurement. The procedures of PSP calibration and PSP film cooling experiments are accomplished with a constant environmental temperature of $22 \pm 0.5^{\circ} \mathrm{C}$

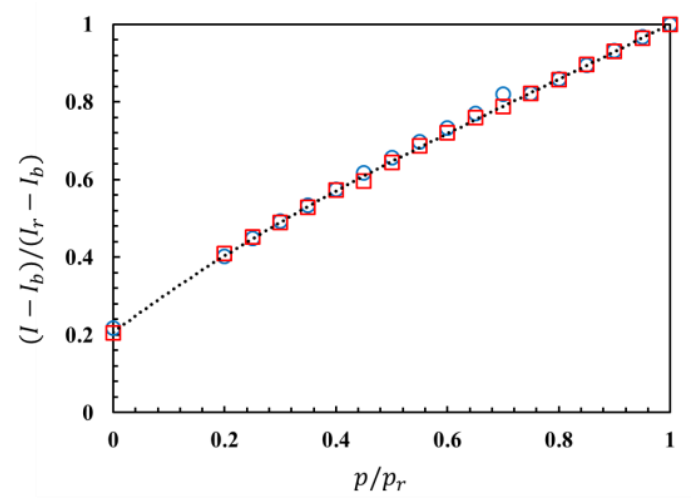

Figure 3 Calibration curve for PSP

\section{Generation of the oscillating mainstream flow}

In order to generate the periodic oscillating mainstream, the rotating shutter was installed at the downstream of the test section (Seo H J et al, 1998). As shown in the Figure 1, the rotating shutter is installed at approximately $40 \mathrm{D}$ downstream from the second-row cooling holes, which can avoid the upstream shedding vortex interference. The shutter blades are driven by step motor. With the Hall angular sensor inside the motor, it would not only make a stable running, but also transport the phase information of the blade to the host PC. During the shutter rotation, the local static pressure would periodic alter which led to the mainstream oscillation.

As the shutter rotated, the velocity of mainstream would act as sinusoidal behaviour. Moreover, the length and thickness of the rotating blades are fixed with $145 \mathrm{~mm}$ and 5 $\mathrm{mm}$ respectively, but the width of them is adjustable which determines the amplitude of flow oscillation $(A)$. The amplitude can be described as $A=\left(\widetilde{U}_{\infty, \max }-\widetilde{U}_{\infty, \min }\right) /$ $2 \bar{U}_{\infty}$, where $\bar{U}_{\infty}$ is the mean velocity of the mainstream, $\widetilde{U}_{\infty, \max }$ and $\widetilde{U}_{\infty, \min }$ are the maximum and minimum phase averaged incoming flow velocity that were obtained by taking the mean of 200 cycles at each phase.

The shutter rotating speed was depended on the pulse signal from host computer program. After conducting a series of preliminary hot-wire test by altering the frequency of shutter rotation and the width of the rotating blade, based on the fixed amplitude of freestream flow, we choose the 80 $\mathrm{mm}$ wide blade (with corresponding block ratio 80\%), and 5 $\mathrm{Hz}$ and $25 \mathrm{~Hz}$ rotating frequency as the oscillating 
experimental conditions. As the Figure 4 shows, the mainstream behaved as a sinusoidal curve, and the amplitude were $10.4 \%$ and $10 \%$, with frequency $5 \mathrm{~Hz}$ and $25 \mathrm{~Hz}$ respectively.

Regard the steady mainstream $\left(\bar{U}_{\infty}=8 \mathrm{~m} / \mathrm{s}\right)$ as baseline, we study the effects of the frequency of the oscillating mainstream $(f)$ under a fixed amplitude. The oscillating

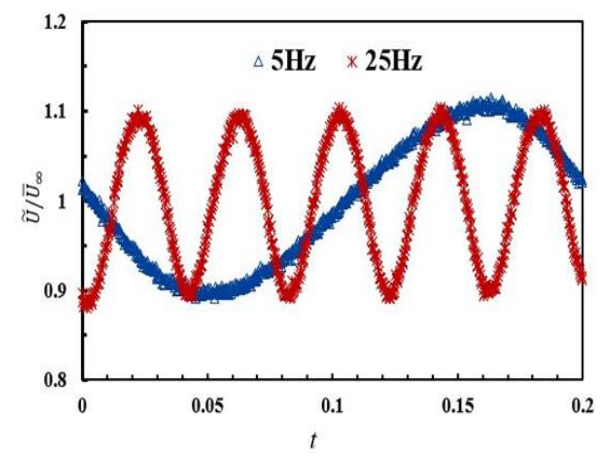

Figure 4 Velocity distribution of oscillating mainstream

Table 1 Experimental parameters corresponding to oscillating frequencies

\begin{tabular}{|c|c|c|c|c|c|c|}
\hline$f(\mathrm{~Hz})$ & $A$ & $\bar{U}_{\infty}$ & $M$ & $S t_{c}$ & $S t_{s}$ & $S t_{\infty}$ \\
\hline \multirow{2}{*}{0} & \multirow{2}{*}{0} & \multirow{2}{*}{$8 \mathrm{~m} / \mathrm{s}$} & 0.4 & 0 & \multirow{2}{*}{0} & \multirow{2}{*}{0} \\
\hline & & & 0.8 & 0 & & \\
\hline \multirow{2}{*}{5} & \multirow{2}{*}{$10.4 \%$} & \multirow{2}{*}{$6.4 \mathrm{~m} / \mathrm{s}$} & 0.4 & 0.4 & \multirow{2}{*}{0.074} & \multirow{2}{*}{0.047} \\
\hline & & & 0.8 & 0.2 & & \\
\hline \multirow{2}{*}{25} & \multirow{2}{*}{$10 \%$} & \multirow{2}{*}{$6.9 \mathrm{~m} / \mathrm{s}$} & 0.4 & 2.4 & \multirow{2}{*}{0.399} & \multirow{2}{*}{0.252} \\
\hline & & & 0.8 & 1.2 & & \\
\hline
\end{tabular}

frequencies are closed relative to Strouhal number of coolant and free stream. Typically, coolant Strouhal number $\left(S t_{c}=\right.$ $\left.2 \pi f L / \bar{U}_{c}\right)$ varies from 0.2 to 6.0 for an operating turbine. When the value of $S t_{c}$ is higher, this illustrates the period of coolant flows from the holes entry to the exit is long enough that the alteration of the velocity of mainstream is drastic, which may cause the cooling film unsteadiness. According to Ligrani (Ligrani P.M. et al,1996), the behaviour of cooling film would change from quasi- and non-quasi-steady during the $S t_{c}$ is 1 2. The parameters of experiment conditions are shown in Table 1 , where the blowing ratio $\left(M=\rho_{c} \bar{U}_{c} /\right.$ $\left.\rho_{\infty} \bar{U}_{\infty}\right)$ is set as 0.4 and 0.8 which is based on the mean velocity of coolant and mainstream, and the $S t_{\infty}$ and $S t_{s}$ are mainstream Strouhal number $\left(S t_{\infty}=2 \pi f \delta / \bar{U}_{\infty}\right)$ and hole spacing Strouhal number $\left(S t_{s}=2 \pi f s / \bar{U}_{\infty}\right)$ which is caused by the delay from the first-row cooling holes.

In present study, the PSP measurements were analysed in terms of " free-run" and "phase-locked" modes, respectively. As the free-run mode, the experimental images were recorded continuously by the high-speed camera, and were further used to calculated the time-averaged adiabatic effectiveness $(\bar{\eta})$. As the phase-locked mode, the phase information from the Hall angular sensor which also represented the phase of oscillating mainstream was transported to host computer by NI device. Then, the pulse signal of each phase was used to trigger the high-speed camera to record. The phases varied from $0^{\circ}$ to $90^{\circ}$ and were equally divided to 9 groups with $45^{\circ}$ interval. We took the average of 150 cycles at each phase to obtain the phaseaveraged effectiveness $(\tilde{\eta})$.

\section{RESULTS AND DISCUSSION}

\section{Validation of the adiabatic effectiveness measured by fast-PSP technique}

For verifying the accuracy of our PSP measurement results, we covered the inlet of first-row cooling holes and took the results of one cooling hole to compare with open

literature where these results were measured under similar steady conditions, as shown in Figure 5. It should be noted that the centreline results were extracted along the streamwise direction and the laterally averaged results were computed by averaging the effectiveness along the spanwise direction (i.e., $-1.5 D \leqslant z \leqslant 1.5 D$ ). From the Figure 5 , it clearly showed both the centreline and the laterally averaged profiles were consistent with the measurement of Schmidt et al (Schmidt et al, 1996). Therefore, the fast-PSP technique will be used in the present study to quantify the effectiveness over the surface. According to conclusion of Johnson et al (Johnson et al, 2016), the relative uncertainty for the timeaveraged effectiveness was estimated to be within $5 \%$ for

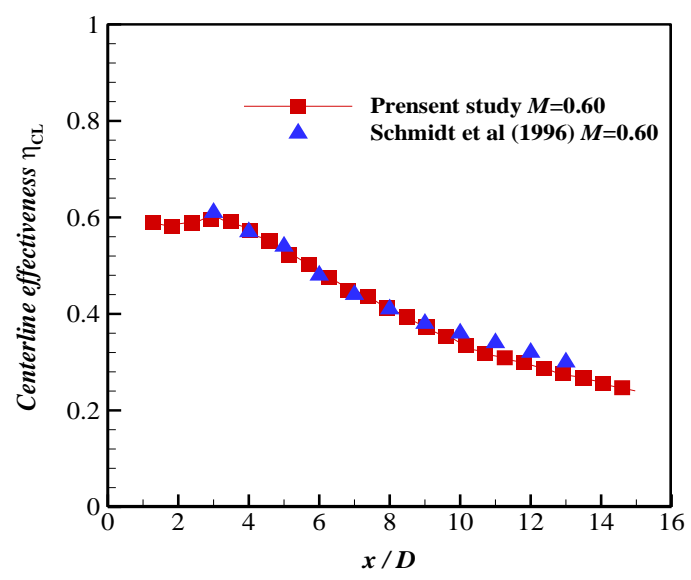

(a) Centreline film cooling effectiveness

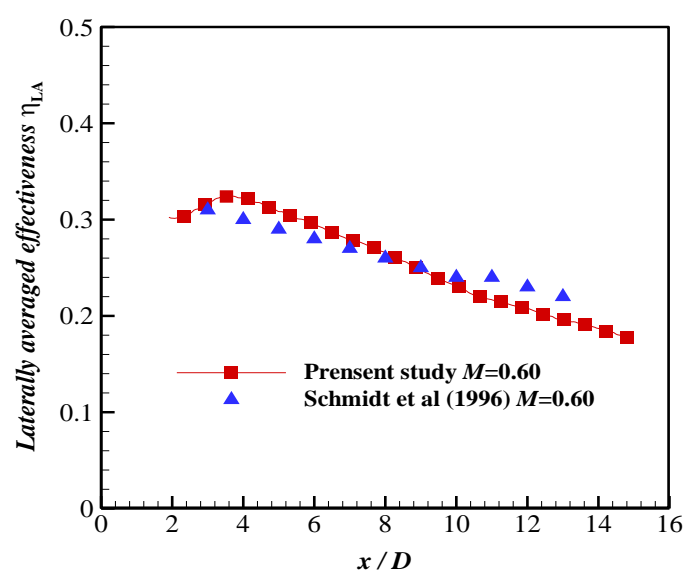

(b) Laterally averaged effectiveness

Figure 5 Comparison of present study with open literature 
$\eta=0.4$ and $7 \%$ for $\eta=0.3$, while for the phase-averaged effectiveness was estimated to be within $7 \%$ for $\eta=0.4$ and $10 \%$ for $\eta=0.3$. These uncertainties were reference of $95 \%$ confidence interval based on two standard deviations, which were estimated using PSP calibration, the statistic of the acquire imaged, and the biases of experimental equipment.

\section{Time-averaged film cooling results}

The time-averaged effectiveness $\bar{\eta}(x, z)$ at $M=0.4$ and 0.8 were calculated to determine the ensemble effect of freestream oscillations on film cooling effectiveness, which were acquired by taking the average of the instantaneous effectiveness $\bar{\eta}(x, z, t)$. The time-averaged effectiveness elucidates the temporal effect of the mainstream oscillations to some degree, and could be obtained:

$$
\bar{\eta}(x, z)=\frac{1}{t_{1}} \int_{0}^{t_{1}} \eta(x, z, t)
$$

where the $t_{1}$ is the acquisition time of free run mode.

\section{Time-averaged effectiveness of baseline}

First of all, the mainstream oscillation effects of single hole film cooling effectiveness were set as the baseline, and for understanding the baseline, the time-averaged results of single row were analysed by covering the first-row cooling holes.

During the experiment, the oscillating frequency was varied from $0 \mathrm{~Hz}$ to $25 \mathrm{~Hz}$. As the Figure 6 (a) showed, generally, the effectiveness values were found to decrease monotonously as the frequency increased at the blowing ratio $M=0.4$. For $5 \mathrm{~Hz}$ case, the reduction near the hole was obvious, and the decrement gradually reduced along the streamwise, which was similar with Zhou's conclusion (Zhou et al, 2018). But for $25 \mathrm{~Hz}$ case, a dramatic reduction came out, only the near hole region was mildly covered by coolant. It may be due to the high $S t_{c}=2.4$. When the coolant wanted to inject out, because of the violent oscillation of the mainstream, the coolant was blown off without coverage. With fixed flow rate of coolant relied on the mean velocity of freestream, the coolant could struggle to form a protection film when the mainstream velocity reached a trough. Figure 7 described the profiles of the effectiveness. Both centreline and laterally averaged results depicted the consistent trend, compared with Figure 6 (a). When $f=5 \mathrm{~Hz}$, slight reductions with $7 \%$ and $8 \%$ for centreline and laterally averaged respectively existed at region of $x<4 D$, and negligible effects at downstream with limited oscillations. When $f=25$ $\mathrm{Hz}$, due to the fiercely vibration of mainstream, around $70 \%$ decrements of effectiveness appeared. And the value went down to lower than 0.2 , which presented a phenomenon similar to the jet pulsing film cooling (Coulthard et al, 2007; Muldoon et al, 2009). Thus, to some extent, higher coolant Strouhal number may cause the coolant injection pulsations at a lower blowing ratio.

Figure 6 (b) showed the time-averaged effectiveness contour at blowing ratio $M=0.8$. For steady condition, a bottleneck was observed at region of $x<2 D$, implying a jet

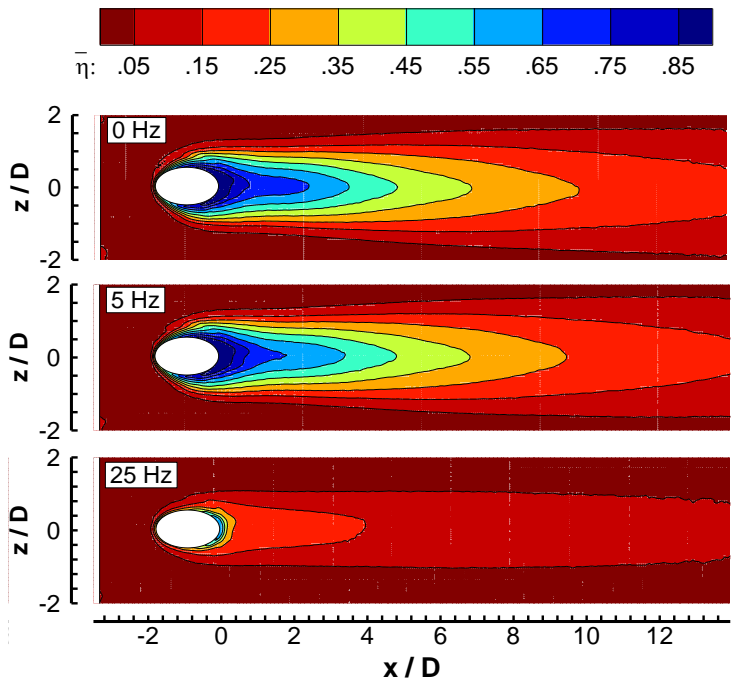

(a) $M=0.4$

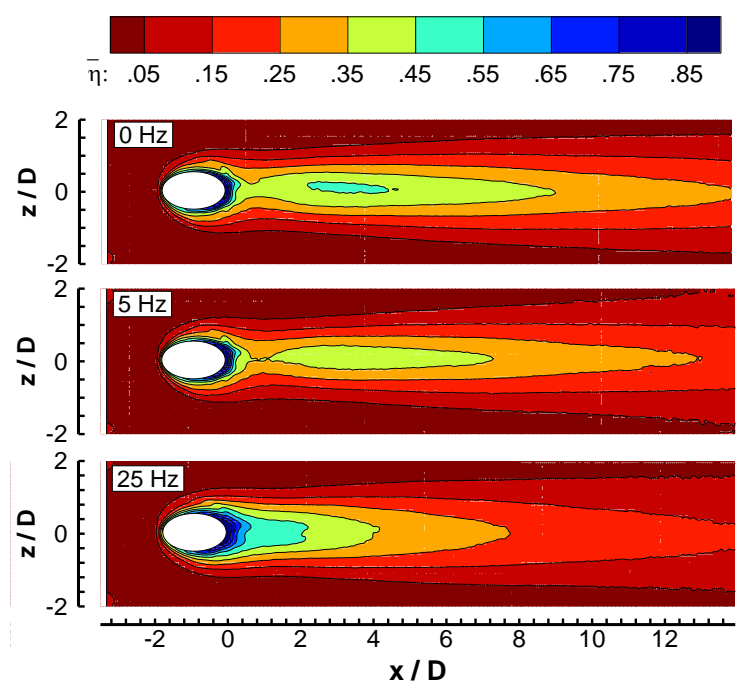

(b) $M=0.8$

Figure 6 Measured time-averaged effectiveness contour for single hole at blowing ratio (a) $M=0.4$ and (b) $M=0.8$

take off and reattachment events. Clearly, the periodic freestream did not alleviate the jet separation with frequency $5 \mathrm{~Hz}$. Moreover, the effectiveness was found to continually reduce along the streamwise direction, and the reduction was about $13 \%$ referred to Figure 7 . With the frequency increasing to $25 \mathrm{~Hz}$, the separation event was prevented by the freestream. The coolant was forced to attach the surface that led to an augment with $25 \%$ of effectiveness near the injection hole. As the interaction between coolant and mainstream was gradually weakened at region of $x>2 D$, the positive effect of oscillations would fade, then the negative effect had contributed to up to $29 \%$ diminution along the downstream. These results could also be found in Beak's conclusion (Beak et al, 2016). When the mainstream oscillating frequency increased, the amplitude of coolant flow rate oscillations for $25 \mathrm{~Hz}$ was higher than $5 \mathrm{~Hz}$ and the coolant injection velocity was lower temporally during a 
period. This led coolant which tended to lift off at $M=0.8$ touching to the wall periodically during these low velocities. Under the oscillating mainstream with fixed amplitude, the effect of oscillations was detrimental especial for higher frequency and lower blowing ratio, and had limited benefit for high blowing ratio.

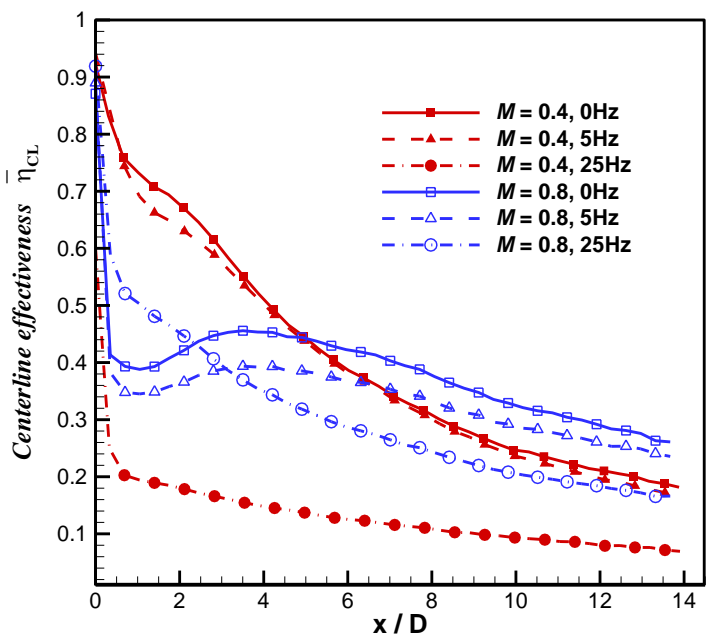

(a) Centreline effectiveness profiles

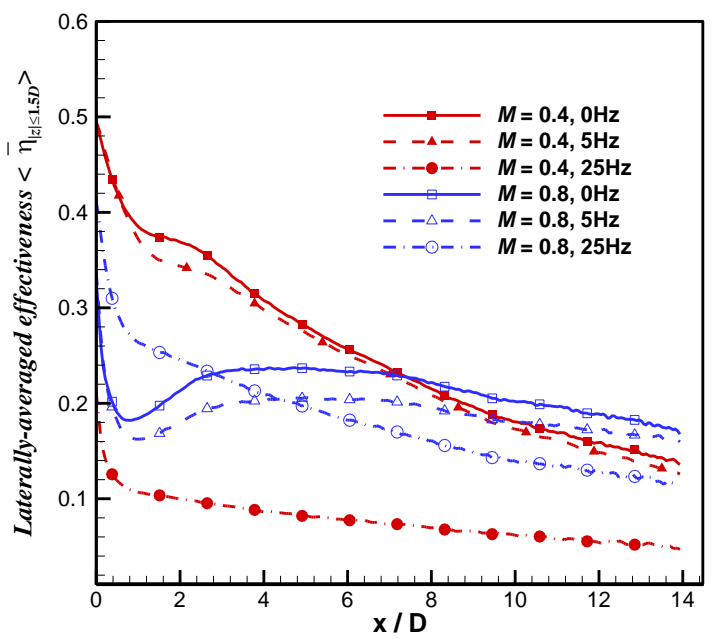

(b) Laterally averaged effectiveness profile

Figure 7 Measured effectiveness of single hole as a function of mainstream oscillation frequency (a) $M$ $=0.4$ and (b) $M=0.8$

\section{Time-averaged effectiveness of double-row holes}

Figure 8 described the measured time-averaged adiabatic effectiveness of the in-line arrangement holes. For $M=0.4$ cases, clearly shown by the footprint, as the oscillating frequency went up, the global effectiveness gradually went down. In detail, compared with steady flow, there was slight effectiveness variation at the region $x<4 D$, but a distinct difference at the further downstream, with $f=5$ $\mathrm{Hz}$. The laterally averaged effectiveness taken from $-4 D \leqslant z$ $\leqslant 4 D$ also indicated this event, shown in Figure 10 (a). The reduction was negligible at $x<6 D$ due to the averaged effect, and a $6 \%$ decrement arose at $x=12 D$. This was different from the counterpart of single hole which reduced at the near hole region. Because of the first-row holes existent, the boundary layer of the second-row thickened which enable the second jet to penetrate deeper into the mainstream (Sinha et al, 1990) so that the oscillation effect was restrained. The protection behaviour of upstream row could be seen obviously at $f=25 \mathrm{~Hz}$. The coverage contour was similar

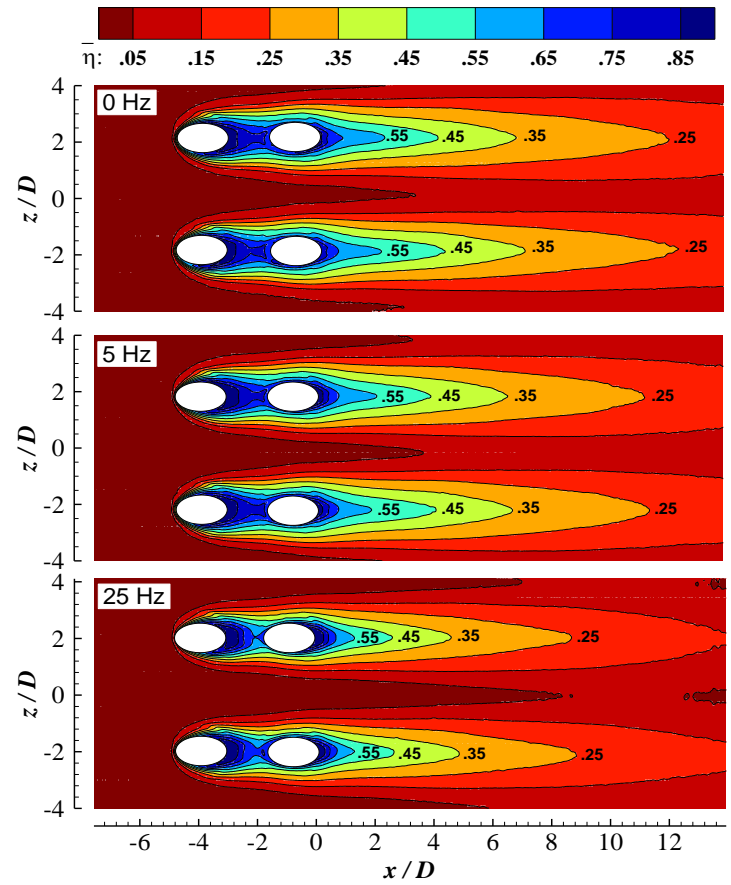

(a) $M=0.4$

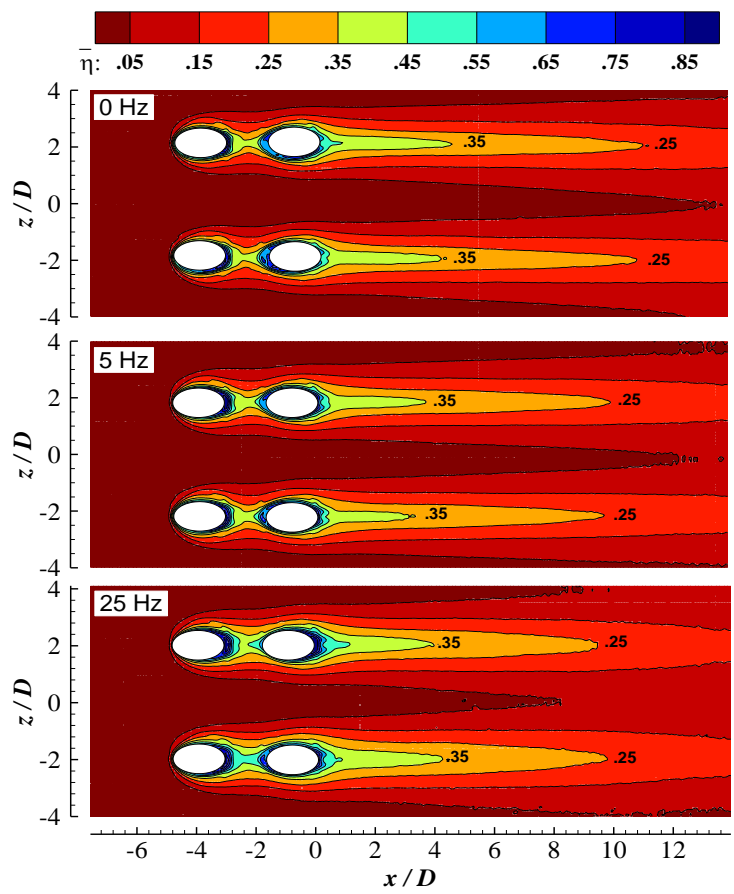

(b) $M=0.8$

Figure 8 Measured time-averaged effectiveness contour for In-line row holes at blowing ratio (a) $M=$ 0.4 and (b) $M=0.8$ 
with the counterpart of lower unsteady flow and the reduction was decrease from over $70 \%$ to around $21 \%$, compared with baseline, that could ensure a better coolant coverage under high unsteady mainstream.

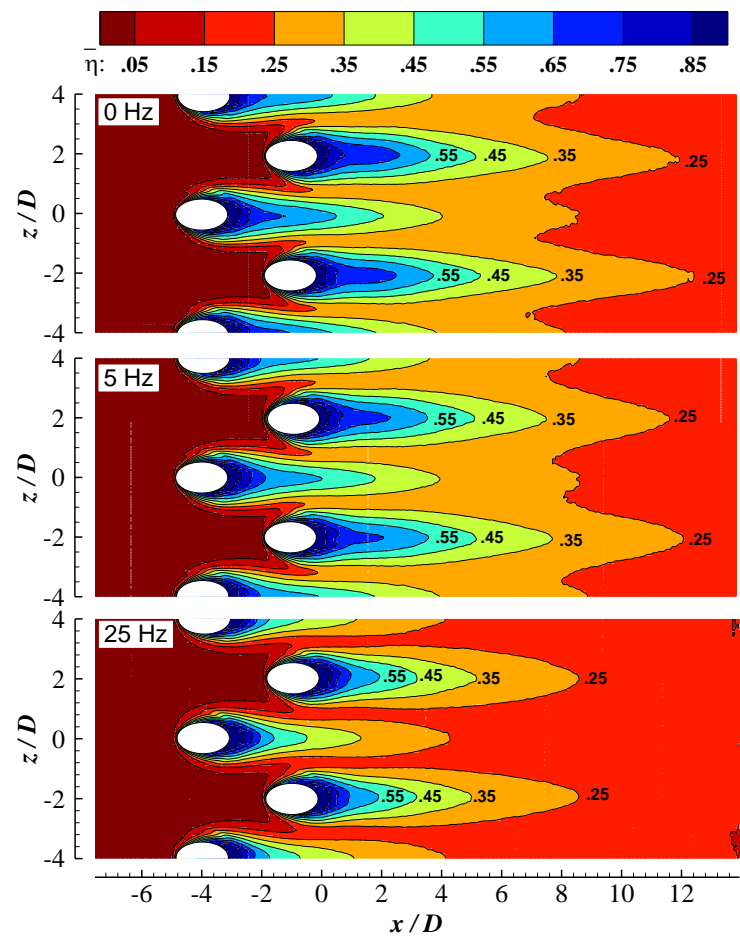

(a) $M=0.4$

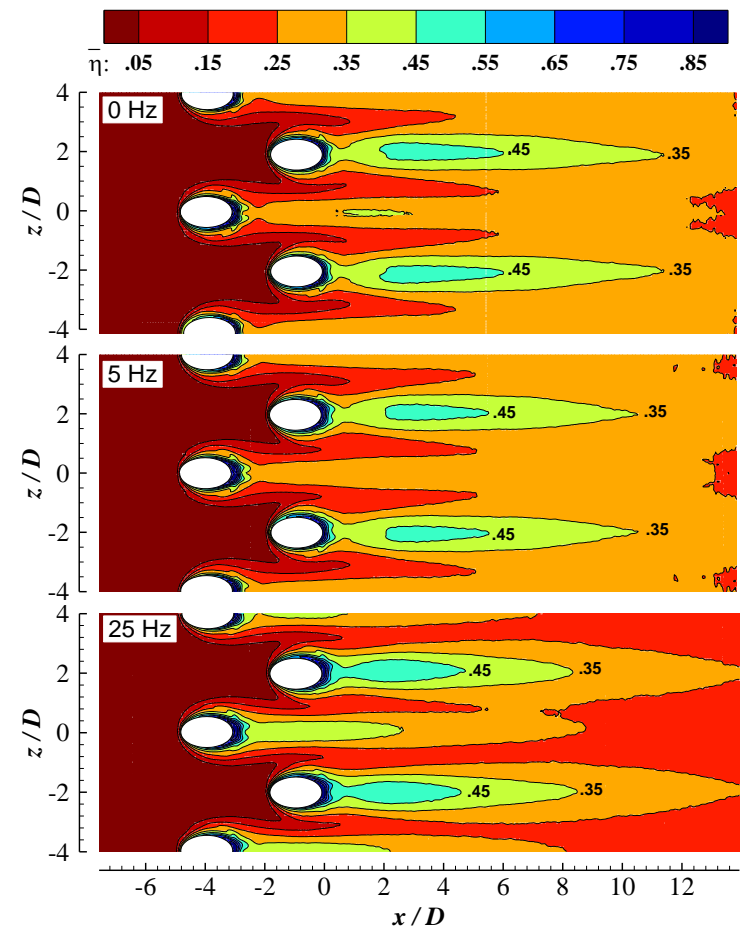

(b) $M=0.8$

Figure 9 Measured time-averaged effectiveness contour for Staggered row holes at blowing ratio (a) $M=0.4$ and (b) $M=0.8$
For $M=0.8$ cases of the in-line arrangement, as the Figure 8 (b) showed, the global trend was consistent with baseline (i.e. decreased firstly and then increased), but at 5 $\mathrm{Hz}$ periodic mainstream the double-row effectiveness was

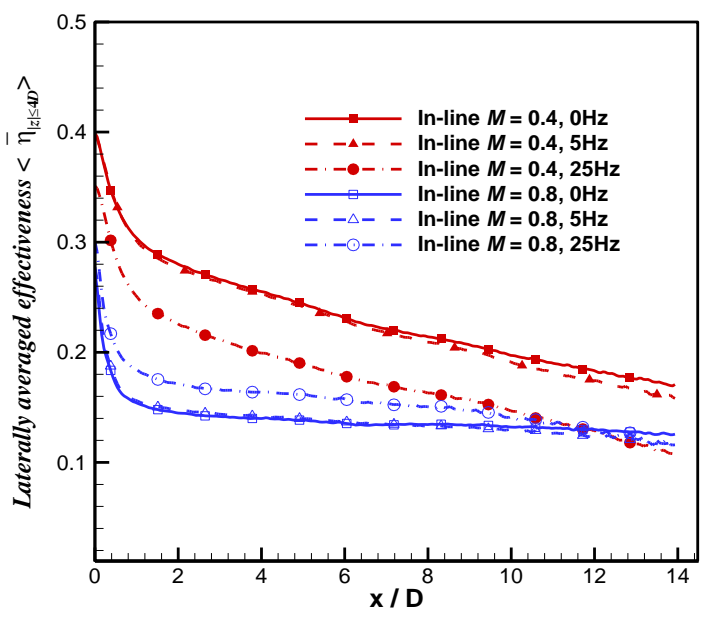

(a) In-line row results profiles

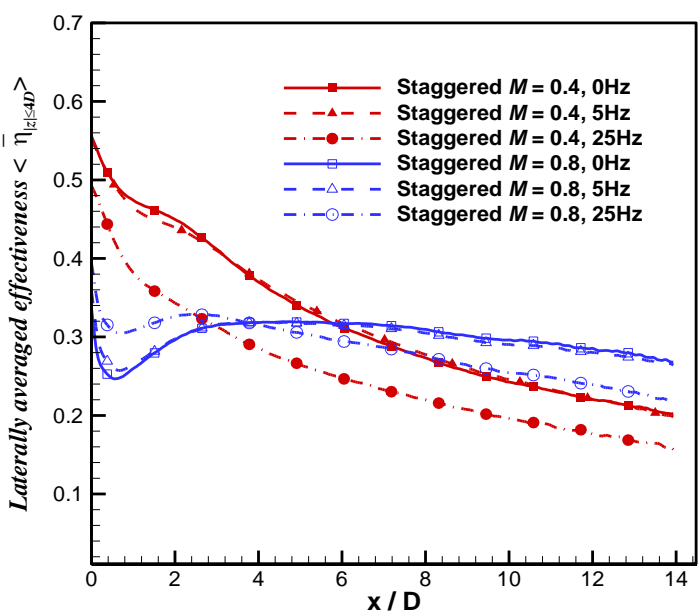

(b) Staggered row results profiles

Figure 10 Measured time-averaged effectiveness for double-row holes varying at different oscillating frequencies

more like a behaviour of steady condition and there arose a total augment which was about $18 \%$, not just at the region closed to the hole, at $25 \mathrm{~Hz}$ mainstream.

Figure 9 displayed the time-averaged adiabatic effectiveness of the staggered arrangement holes. Generally, the behaviours of coolant had the same trend with single hole, whereas some details differed from the baseline due to the hole's interaction. For $M=0.4$ cases, the negative effect caused by unsteady freestream was restrained by the interaction which was mentioned by Jiang (Jiang et al, 2018) at $f=5 \mathrm{~Hz}$, so that the effectiveness profile was closed to the steady case referred to Figure 10 (b). And for $25 \mathrm{~Hz}$ case, the cooling effectiveness decreased $22 \%$ compared with the steady flow case. For $M=0.8$ cases, the results were similar to the counterparts of the in-line arrangement holes at $f=5$ $\mathrm{Hz}$, but when the frequency was $25 \mathrm{~Hz}$, the positive events 
were not global, and only existed at the region of $x<4 D$. To be more specific, along the streamwise direction, the peak of effectiveness increment was located $x=1 D$ with $50 \%$, and then the increment gradually reduced even to be negative. At $x>8 D$, the relative reduction was about $17 \%$.

In general, as to different blowing ratio cases, the results of double-row holes were similar to the counterparts of the single hole. To be specific, the oscillation had an unchanged negative effect at lower blowing ratio, and may have a positive effect at higher blowing ratio. However, due to the protection from the upstream row, the in-line arrangement may provide a better performance whereas the staggered arrangement behaved more likely to the single hole.

\section{Phase-averaged film cooling results}

During the mainstream oscillation, the coverage of the coolant may fluctuate at the same time, which would result in the core component exposes to the hot gas directly in the real engine. Thus, analysing the coolant coverage distribution at each phase is worthwhile to evaluate a cooling performance. The phase-averaged film cooling effectiveness $(\tilde{\eta})$ represents the spatial behaviour of the cooling film to some degree, which could be expressed as:

$$
\tilde{\eta}(x, z, t)=\frac{1}{N} \sum_{n=0}^{N} \eta(x, z, t+n \tau) .
$$

where the $N$ is the number of cycles to take average, $\tau$ is the oscillation period.

Through the former discussion of the time-averaged results, the higher oscillating frequency or higher coolant Strouhal number may cause significant influences to film cooling performance. Therefore, the following discussion about phase-averaged results fixed the oscillating frequency at $25 \mathrm{~Hz}$.

\section{At blowing ratio $M=0.4$}

Figure 11 depicted the adiabatic effectiveness distributions of different hole arrangements at each phase with $M=0.4$ and $f=25$. In these cases, the coolant Strouhal number $\left(S t_{c}=2.4\right)$ was maximum among present study. As the Figure 11 (a) showed, with the phase of periodic mainstream changing, the coolant was only squeezed out at the peak of the freestream velocity (i.e. $\theta=90^{\circ}$ ) and then disappeared gradually. This event could be explained that the static pressure of mainstream was minimum, which enabled the coolant inside the plenum with constant static pressure to inject out. On the other hand, the coolant Strouhal number was high enough so that it would take longer time to make the coolant out, meanwhile the velocity of mainstream may already change several times. In all, there was a clear pulsation of coolant jet for single hole film cooling with oscillating mainstream. Figure 11 (b) showed the results of in-line holes. It could be seen that no obviously separation of coolant was at each oscillating phase. Moreover, the fluctuations of the cooling film acted forward and backward with the phase changing. It looked like the mainstream pushed the film backward or enlarged the film along the streamwise direction rather blew it away from the plate surface. Thus, due to the interaction between upstream row jet and mainstream, the downstream row jet could cover the surface effectively which made a better cooling protection.

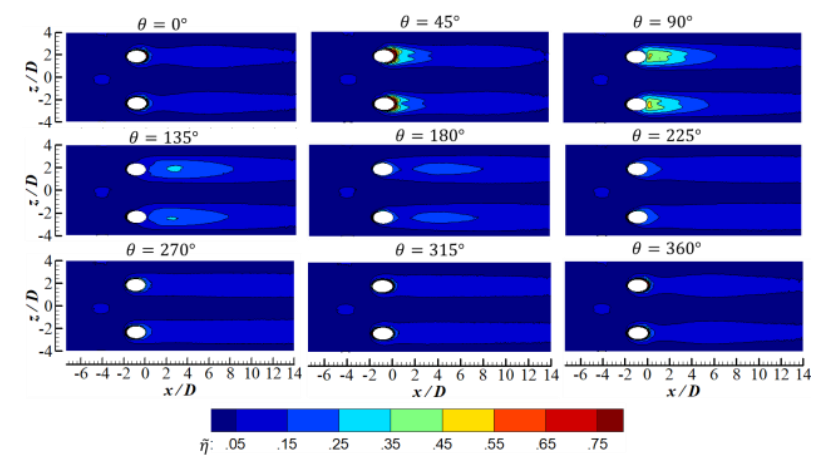

(a)

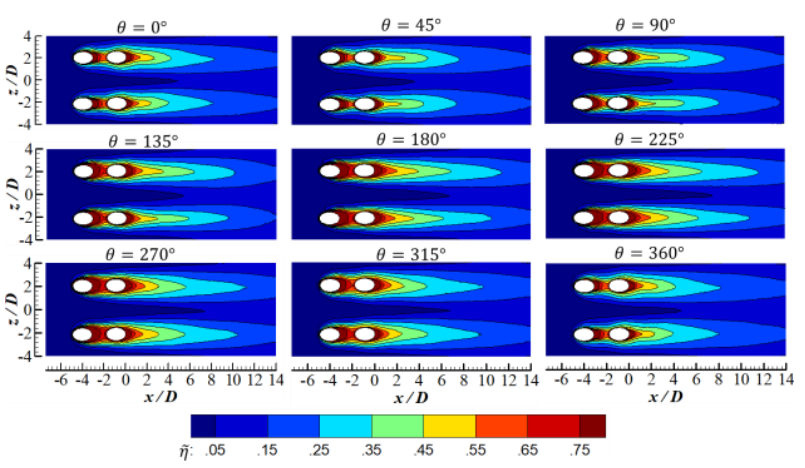

(b)

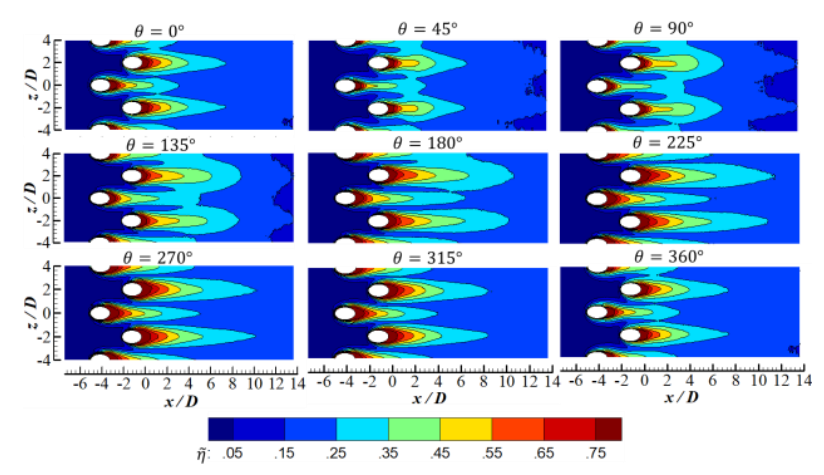

(c)

Figure 11 Phase-averaged adiabatic effectiveness distributions at $M=0.4$ and $f=25 \mathrm{~Hz}$ : a) single hole, b) in-line holes, c) staggered holes

Figure 11 (c) showed the effectiveness distribution of staggered holes. As the picture showed, differed from the single hole case, the coolant coverage always existed at each phase. According to the conclusion of Jiang (Jiang et al, 2018), the counter-rotating-vortex pair of the first-row jet would offset the vortex pair of the second-row which may make the downstream coolant well attached to the wall, instead let the oscillation mainstream blow it away. But, if we focused on the region near $x=3 D$ in the Figure 11 (c), the area of coolant coverage was fat or thin, altered with the changed phase. Exactly, when the phase varied from $0^{\circ}$ to $90^{\circ}$, the coolant of second-row blew downstream that enlarged the coverage area. when the phase varied from $90^{\circ}$ 
to $360^{\circ}$, the coverage gradually slimmed, gained, waited for the next cycle. In this way, both the single hole and the staggered holes had the coolant pulsation event due to the mainstream oscillations.

\section{At blowing ratio $M=0.8$}

Figure 12 described the adiabatic effectiveness distributions of different hole arrangements at each phase with $M=0.8$ and $f=25$. With high enough blowing ratio, the coolant would take off firstly and then reattach. And, in these cases, the coolant Strouhal number $\left(S t_{c}\right)$ was 1.2. As the Figure 12 (a) showed, the periodic coolant coverage strongly depended on the phase of mainstream. When the velocity of mainstream was at the peak phase $\theta=90^{\circ}$, the coolant coverage reached minimum which was different from the $M$ $=0.4$. It could be explained that because $S t_{c}$ was not big enough, the coolant could still inject out during the mainstream oscillation period which also played a major role

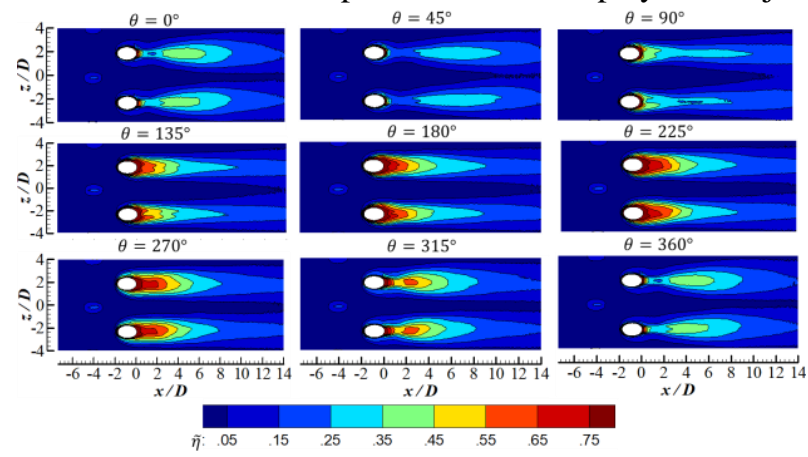

(a)

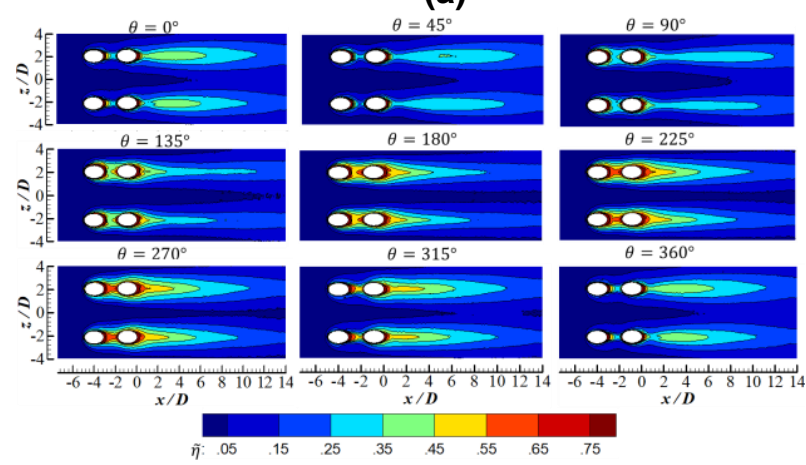

(b)

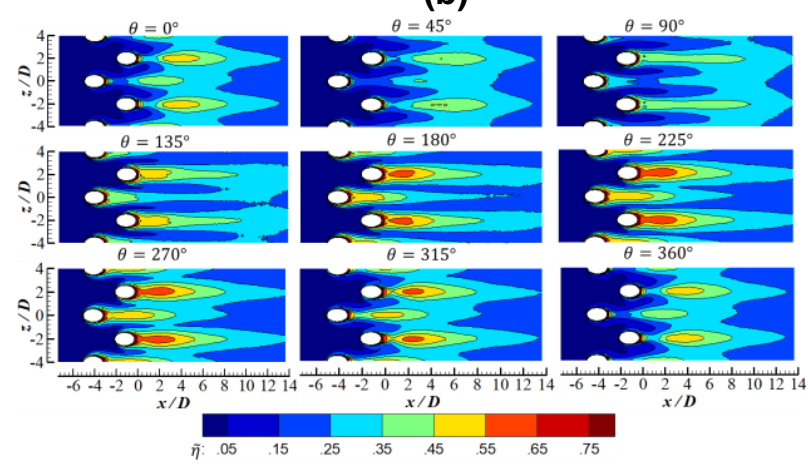

(c)

Figure 12 Phase-averaged adiabatic effectiveness distributions at $M=0.8$ and $f=25 \mathrm{~Hz}$ : a) single hole, b) in-line holes, c) staggered holes in the cooling process. Moreover, when the phase angle is $270^{\circ}$, the static pressure of freestream was big enough to push the coolant attached to the wall which made a high cooling effectiveness. And the events of the coolant at other phases were in between. Figure 12 (b) showed the results of in-line holes. As mentioned above, the upstream injection would thicken the boundary layer downstream which made the second-row injection deeper in to the mainstream. Thus, the separation of the coolant could not be restrained due to the high blowing ratio. In all, the in-line arrangement could not form a stable coolant protection as the separation was dominant at high blowing ratio.

Figure 12 (c) showed the results of staggered holes. It could be seen that the whole trend of staggered cooling holes was similar to the single row. It also supplied a periodic coolant injection (i.e. the peak at $\theta=90^{\circ}$ and the bottom at $\theta=270^{\circ}$ ). Compared with the single-row, the augment of effective caused by the oscillation effect acted more averaged effect among the downstream, rather just arose near the cooling holes, which may due to the interaction of the vortex pair of the double-row.

\section{Area-averaged phase effectiveness}

The area-averaged phase effectiveness was further calculated (i.e. in the region of $0<x<14 D$ and $-4 D<z<$ $4 D)$ to clarify the dependence of adiabatic effectiveness in relation to phase angle, shown in Figure 13. As expected, all of the curves followed the sinusoidal trend. At low blowing ratio $M=0.4$, the variation amplitude which reflected the extent of coolant unsteadies of in-line holes less than staggered holes, but for high blowing ratio $M=0.8$, it was reversed. Moreover, there was a phase lag of the peak of the area-averaged effectiveness between these two blowing ratios, around $225^{\circ}$ and $270^{\circ}$ respectively. It could be explained by the reattachment at high blowing ratio. Overall, the staggered arrangement which not only provided a relatively good stability but also a higher area-averaged effectiveness at high blowing ratio. At low blowing ratio, the in-line arrangement acted more stable, although the relatively lower area-averaged effectiveness.

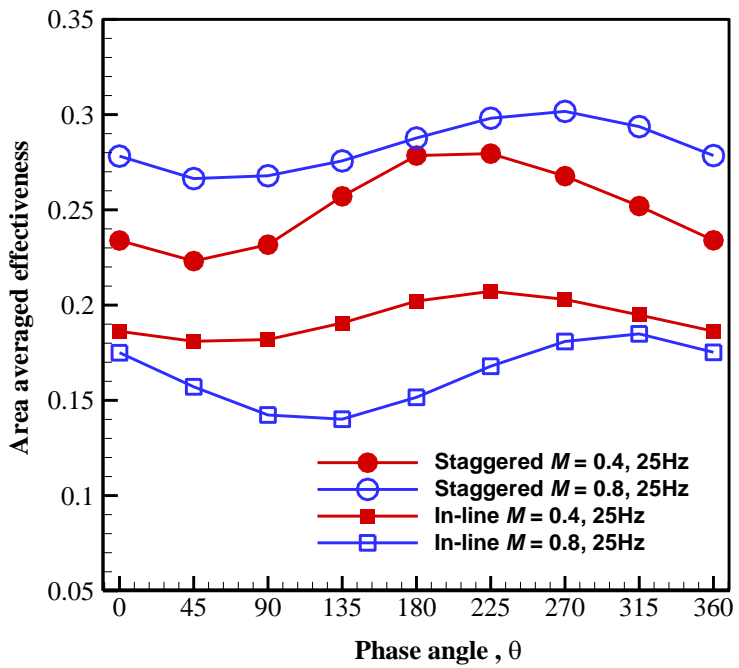

Figure 13 The area-averaged phase effectiveness for double-row holes 


\section{CONCLUSIONS}

Experimental results were presented to describe the effect of the mainstream oscillation on the double-row film cooling effectiveness. While the single hole was treated as the baseline, the double-row film cooling cases with periodic freestream were assessed in detail to explore the frequency effect (i.e. set to $5 \mathrm{~Hz}$ and $25 \mathrm{~Hz}$ with fixed amplitude) on adiabatic effectiveness. The results included two aspects which was the time-averaged results and the phase-averaged results, respectively indicted the temporal and spatial variation on the adiabatic film cooling effectives.

The time-averaged results uncovered that, both the inline rows and staggered rows could alleviate the negative effects of mainstream oscillations and enhance the positive effects, compared with the baseline. Especially, at the higher frequency $25 \mathrm{~Hz}$ and blowing ratio 0.4 , the $70 \%$ reduction of effectiveness in baseline changed to $22 \%$ counterpart. As to blowing ratio 0.8 , the in-line arrangement could provide a global augment of the effectiveness at $f=25 \mathrm{~Hz}$.

Although the oscillating amplitude $A$ was close among the different frequencies, the low frequency mainstream played a limited role in the film cooling process. The phaseaveraged chosen at $f=25 \mathrm{~Hz}$ indicated that, a pulsation event would arise in baseline case and double-row arrangement would cancel this phenomenon due to the interaction between the upstream row and the freestream. The double-row could behave better than the single hole. Moreover, the staggered arrangement had relatively good stability than the in-line at high blowing ratio, but at lower blowing ratio reversed.

To sum up, compared with baseline, the double-row had a higher effectiveness in the time-averaged result, and a more stability of coolant coverage in the phase-averaged result.

\section{NOMENCLATURE}

A oscillating amplitude, $\left(\widetilde{U}_{\infty, \max }-\widetilde{U}_{\infty, \min }\right) / 2 \bar{U}_{\infty}$

$D$ diameter of the coolant injection hole

$D_{S} \quad$ concentration diffusion coefficient

$D R \quad$ coolant to mainstream density ratio, $\rho_{c} / \rho_{\infty}$

$f \quad$ oscillating frequency of mainstream

$L \quad$ entry length of the coolant hole

Le Lewis number, $\alpha / D_{s}$

$M \quad$ blowing ratio, $\rho_{c} \bar{U}_{c} / \rho_{\infty} \bar{U}_{\infty}$

$M W \quad$ coolant to mainstream molecular weight ratio

$p \quad$ hole pitch

$s \quad$ hole spacing

$S t_{c} \quad$ coolant Strouhal number, $2 \pi f L / \bar{U}_{c}$

$S t_{s} \quad$ hole spacing Strouhal number, $2 \pi f s / \bar{U}_{\infty}$

$S t_{\infty} \quad$ mainstream Strouhal number, $2 \pi f \delta / \bar{U}_{\infty}$

$T_{a w} \quad$ adiabatic wall temperature

$T_{c} \quad$ coolant temperature

$T_{\infty} \quad$ mainstream temperature

$x, y, z \quad$ streamwise, normal and spanwise coordinates

\section{Greek symbols}

$\alpha \quad$ thermal diffusion coefficient

$\delta \quad$ boundary layer thickness $\delta^{* *} \quad$ momentum boundary thickness

$\rho \quad$ density of gases

$\eta \quad$ instantaneous film cooling effectiveness

$\bar{\eta} \quad$ time-averaged film cooling effectiveness

$\tilde{\eta} \quad$ phase-averaged film cooling effectiveness

$\theta \quad$ phase angle

$\tau \quad$ oscillation period

\section{Abbreviations}

fast-PSP

fast-response pressure sensitive paint

\section{Superscripts}

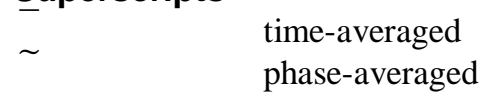

\section{ACKNOWLEDGMENTS}

The authors gratefully acknowledge the financial support for this study from the Natural Science Foundation of China $(11725209,51806138)$ and the Shanghai Sailing Program (18YF1411300).

\section{REFERENCE}

Baek S. Il., Yavuzkurt S. (2016). Effects of oscillations in the main flow due to thermo acoustic fields in a gas turbine combustor on film cooling, in: ASME Turbo Expo 2016 Turbomach. Tech. Conf. Expo., ASME, https://doi.org/10.1115/GT2016-56402.

Baek S. Il., Yavuzkurt S. (2017). Effects of Oscillations in the Mainstream on Film Cooling at Various Blowing Ratios. Heat Transf., vol. 5A, ASME, https://doi.org/10.1115/GT2017-63398.

Bell J. H., Schairer E. T., Hand L. A., Metha R D. (2001) Surface pressure measurements using luminescent coatings 1, Annu. Rev. Fluid Mech. 33 (2001) 155-206, https://doi.org/10.1146/anuurev.fluid.33.1.155.

Bogard D. G., Thole K. A. (2006). Gas turbine film cooling, J. Propuls. Power 22 249-270, https://doi.org/10.2514/1.18034.

Charbonnier D., Ott P., Jonsson M., Cottier F., Köbke T. (2009). Experimental and Numerical Study of the Thermal Performance of a Film Cooled Turbine Platform, Asme Turbo Expo 2009, vol. 3, Pts A B, ASME, https://doi.org/10.1115/GT2009-60306.

Coulthard S. M., Volino R. J., Flack K. A. (2007). Effect of jet pulsing on film cooling, part 1: effectiveness and flow field temperature results. Journal of Turbomachinery, 129 (2). https://doi.org/10.1115/1.2437231.

Gregory J. Asai K. Kameda M. Liu T. Sullivan J. (2008) A review of pressure-sensitive paint for high-speed and unsteady aerodynamics. Proceed. Institut. Mech. Eng., Part G:J. Aerospace Eng. 222(2) 249-290.

Han J., Dutta S., Ekkad S. (2012). Gas Turbine Heat Transfer and Cooling Technology, second ed., CRC Press, New York.

Jiang Y., Ireland P., Capone L., Romero E. (2018). A detailed study of the interaction between two rows of cooling holes. ASME. J. Turbomach. 140 https://doi.org/10.1115/1.4038833.

Khojasteh A., Wang S., Peng D., Yavuzkurt S., Liu Y. Z. (2017). Structure analysis of adiabatic film cooling 
effectiveness in the near field of a single inclined jet: Measurement using fast-response pressure-sensitive paint, Int. J. Heat Mass Transf. 110 629-642, https://doi.org/10.1016/J.IJHEATMASSTRANSFER.2017.0 3.069 .

Ligrani P M, Wigle J M, Ciriello S, et al. (1994). Film cooling from holes with compound angle orientations: Part 1-results downstream of two staggered rows of holes with 3d spanwise spacing. ASME J. Heat Transfer 116 (2) 341352.

Ligrani P. M., Gong R., Cuthrell J. M., Lee J. S. (1996). Bulk flow pulsations and film cooling-I. Injectant behavior, Int. J. Heat Mass Transf. 39 (1996) 2271-2282, https://doi.org/10.1016/0017-9310(95)00286-3.

Liu T, Sullivan J. P. (2005). Pressure and Temperature Sensitive Paints, Springer, Berlin Heidelberg, 2005.

Muldoon F., Acharya S. (2009). DNS study of pulsed film cooling for enhanced cooling effectiveness, International Journal of Heat and Mass Transfer, 52, 13-14, 3118-3127, https://doi.org/10.1016/j.ijheatmasstransfer.2009.01.030.

Schmidt D.L., Sen B., Bogard D. G. (1996). Film cooling with compound angle holes: adiabatic effectiveness, $\begin{array}{lll}\text { ASME. J. Turbomach. } & \text { 118(4):807-813. }\end{array}$ https://doi.org/10.1115/1.2840938.

Scroggin A., Slamovich E. Crafton J. Lachendro N, Sullivan J. (1999) Porous polymer/ceramic composites for luminescence-based temperature and pressure measurement. MRS Online Proceed. Library Archive 590.

Seo H. J, Leea J. S, Ligrani P. M. (1998). The effect of injection hole length on film cooling with bulk flow pulsations, Int. J. Heat Mass Transf. 41 3515-3528, https://doi.org/10.1016/S0017-9310(98)00042-8.

Sinha A. K., Bogard D. G., Crawford M. E. (1990). Gas turbine film cooling: flow field due to a second row of holes. $\begin{array}{llll}\text { ASME. J. } & \text { Turbomach. }\end{array}$ https://doi.org/10.1115/1.2927895.

Sohn D. K., Lee J. S. (1997). The effect of bulk flow pulastions on film cooling from two rows of holes. ASME Turbo Expo 1997, https://doi.org/10.1115/97-GT-129.

Zhou W W, Qenawy M, Liu Y Z, et al. (2019). Influence of mainstream flow oscillations on spatio-temporal variation of adiabatic film cooling effectiveness. International Journal of Heat and Mass Transfer. 129 569579 https://doi.org/10.1016/j.ijheatmasstransfer.2018.09.131. 